\title{
Editorial Expression of Concern: The efficacy of vitamin D combined with clomiphene citrate in ovulation induction in overweight women with polycystic ovary syndrome: a double blind, randomized clinical trial
}

\author{
Radwa Rasheedy $\mathbb{B D}^{1} \cdot$ Hazem Sammour ${ }^{1} \cdot$ Abdellatif Elkholy $^{1} \cdot$ Yasmine Salim $^{2}$
}

Published online: 3 December 2021

(c) Springer Science+Business Media, LLC, part of Springer Nature 2021

The Editor-in-Chief is issuing an Editorial Expression of Concern for this article. After publication concerns were raised about the reporting of this clinical trial. The Head of the Obstetrics and Gynecology Department, Faculty of Medicine, Ain Shams University, has informed the Editorin-Chief that ethics approval was given for this study; however, the documentation is not available. Ain Shams University has not responded to a request to confirm that this study was conducted with appropriate ethical oversight. Radwa Rasheedy, Hazem Sammour, Abdellatif Elkholy and Yasmine Salim have not responded to correspondence from the publisher about this statement.

The original article can be found online at https://doi.org/10.1007/ s12020-020-02315-3.

Radwa Rasheedy

radwaebed@yahoo.com

1 Obstetrics and Gynecology Department, Faculty of Medicine, Ain Shams University, Cairo, Egypt

2 Port Said General Hospital, Port Said, Egypt 